\title{
Do sovereign credit ratings influence regional stock and bond market interdependencies in emerging countries?
}

\author{
Rachel Christopher ${ }^{\mathrm{a}}$, Suk-Joong Kim ${ }^{\mathrm{b}, \bullet}$ and Eliza $\mathrm{Wu}^{\mathrm{c}}$, \\ ${ }^{a}$ Goldman Sachs, Level 42, 1 Farrer Place, Sydney, NSW 2000, Australia \\ ${ }^{\mathrm{b}}$ Discipline of Finance, University of Sydney, Sydney, NSW 2006, Australia \\ ${ }^{\mathrm{c}}$ Finance Discipline Group, UTS Business School, University of Technology, Sydney, NSW \\ 2007, Australia
}

\begin{abstract}
We investigate the permanent and transitory effects of sovereign credit ratings on time-varying stock and bond market correlations with their respective regional markets for a sample of up to nineteen emerging countries over the period from 1 January 1994 to 1 July 2007. We find that stock and bond market co-movements within a region respond heterogeneously to sovereign ratings information. Sovereign ratings and outlooks tend to be positively related to regional stock market co-movements suggesting that there are positive rating spillover effects whereby upgrades provide common benefits for neighboring countries in the region, however downgrades would lead to investors shifting funds from the downgraded market into the surrounding region. In contrast, sovereign rating and outlooks tend to be negatively related to regional bond market comovements suggesting the existence of contagion during periods of ratings and outlook downgrades (negative rating spillover effects). We find the negative influence is concentrated in the countries that have higher foreign currency debt ratings than the regional average.
\end{abstract}

\section{JEL Classification: F3; G14; G15}

Keywords: Emerging markets; financial market linkages; sovereign ratings; stocks; bonds

\begin{abstract}
Acknowledgement:
We thank an anonymous referee for the valuable suggestions that improved this paper. The remaining errors, if any, are our own.
\end{abstract}

• Corresponding author, Tel: +61 29114 0940, Fax: +61 29315 6461, email: sukjoong.kim@sydney.edu.au 


\title{
Do sovereign credit ratings influence regional stock and bond market interdependencies in emerging countries?
}

\begin{abstract}
We investigate the permanent and transitory effects of sovereign credit ratings on time-varying stock and bond market correlations with their respective regional markets for a sample of up to nineteen emerging countries over the period from 1 January 1994 to 1 July 2007. We find that stock and bond market co-movements within a region respond heterogeneously to sovereign ratings information. Sovereign ratings and outlooks tend to be positively related to regional stock market co-movements suggesting that there are positive rating spillover effects whereby upgrades provide common benefits for neighboring countries in the region, however downgrades would lead to investors shifting funds from the downgraded market into the surrounding region. In contrast, sovereign rating and outlooks tend to be negatively related to regional bond market comovements suggesting the existence of contagion during periods of ratings and outlook downgrades (negative rating spillover effects). We find the negative influence is concentrated in the countries that have higher foreign currency debt ratings than the regional average.
\end{abstract}

JEL Classification: F3; G14; G15

Keywords: Emerging markets; financial market linkages; sovereign ratings; stocks; bonds

Acknowledgement:

We thank an anonymous referee for the valuable suggestions that improved this paper. The remaining errors, if any, are our own. 


\section{Introduction}

Throughout recent decades, sovereign credit ratings and their influential roles in both encouraging and potentially destabilizing investment flows into emerging markets have amassed considerable interest, particularly in light of their delayed revisions that intensified various currency crises in the 1990 s and early 2000s. These ratings provided by credit rating agencies reflect the capacity and willingness of sovereign obligors to meet their debt service payments and are based on a broad range of criteria which includes, among other considerations, economic performance, loan default history and political factors. By encapsulating a wide range of factors, these credit risk assessments have been identified as crucial tools for evaluating investment opportunities in emerging markets where problems of asymmetric information can be severe. As a result, the literature aiming to gauge the impacts of sovereign ratings on asset returns has proliferated with the main empirical findings supporting the notion that they significantly influence overall capital flows into stock and bond markets (see Brooks et al., 2004; Cantor and Packer, 1996; Reisen and Von Maltzan, 1999; Reinhart and Rogoff, 2004, Kim and Wu, 2008).

A remarkable feature of these capital flows is that asset returns in neighboring emerging markets are often observed to move in tandem. This is evident in the numerous episodes of financial crises in the recent past, in which sharp capital movements led to substantial devaluations in stock and bond investments not only in the epicenters of the crises but also surrounding countries in the nearby region. ${ }^{1}$ These simultaneous and powerful financial shocks have highlighted the existence of a regional transmission channel through which both information and capitals flow. In the extant literature, strong neighborhood effects are documented and contagion is known to be regional rather than global in nature (Glick and Rose, 1999). This aspect has important implications for investors' portfolio allocation decisions and for policy makers who are entrusted to regulate and to maintain the stability of international financial

\footnotetext{
${ }^{1}$ These include the Asian Financial Crisis (1997-98), the Russian Debt Default (1998), the Brazilian Crisis (1999) and the Argentine Crisis (2001-2002).
} 
systems. For these reasons, focus needs to be placed on monitoring how an emerging market's stock and bond capital flows co-move with those of the overall region and more importantly, to understand what factors significantly influence these patterns.

To date, research on the nature of asset interdependence has been mostly confined to measuring the level of national stock or bond market co-movements with the world market in order to uncover signs that countries are becoming globally interdependent (see Bekaert and Harvey, 1995, 2003; Bekaert, Hodrick and Zhang, 2009; Bracker et al., 1999). Most studies in the literature have been primarily motivated to investigate the contagious effects of financial crises that increased financial linkages in asset returns across geographically proximate nations (see Baig and Goldfajn, 1999; Hernandez and Valdes, 2001; Kaminsky and Reinhart, 1999; Kaminsky and Schmukler, 2002). By measuring the short-term stock or bond market co-movements between neighboring emerging markets, the bulk of existing evidence supports strong contagion and/or negative rating spillover effects during times of financial distress (Ferreira and Gama, 2007; Gande and Parsley, 2005; Kaminsky and Schmukler, 2002);. For example, Baig and Goldfajn (1999) find that co-movements in sovereign bond spreads and stock returns across pairs of South-East Asian countries significantly increased during periods of financial crises.

Given the established evidence of sovereign rating impacts on individual country asset flows, we conjecture that they contain significant informational value that can influence regional asset co-movements. Thus, our aim in this paper is to merge the two prominent strands of literature on sovereign ratings and asset co-movements to determine whether an explicit relationship exists between the two. To the best of our knowledge, the nature of this potential linkage has yet to be fully explored. Our research question is: How do sovereign ratings affect an emerging country's stock and bond market interdependence with its corresponding region in both the short- and long-term? The ratings literature has not previously differentiated between the long-term and transitory impacts of sovereign credit ratings and is missing such a comprehensive study of emerging markets' asset return co-movements. Moreover, there are few studies 
comparing the effects of sovereign credit ratings in both stock and bond markets (besides Pukthuanthong-Le et al., 2007 and Kaminsky and Schmukler, 2002). Whilst it has been documented that rating events in one country has significant spillover effects for other international bond and stock markets in the short-term (see Gande and Parsley, 2005, and Ferreira and Gama, 2007, respectively), it is not clear how they may impact on a country's intra-regional stock and bond market interdependencies over different time-frames. Our work is the closest to that of Chiang, Jeon and $\mathrm{Li}$ (2007) who find that for nine Asian countries during the Asian Financial Crisis, changes in their foreign currency sovereign ratings were significantly related to their pair-wise cross-stock market correlations. Our research first differentiates itself by addressing the shortfall in current understanding between intra-regional market linkages over different time horizons and sovereign credit rating revisions. Secondly, we provide some economic interpretations on why there are cross-country differences in the effects of sovereign ratings information on intra-regional stock and bond market return interdependencies. By employing a dataset of nineteen emerging countries over a recent pre-Global Financial Crisis sample period from 1 January 1994 to 1 July 2007, we conduct extensive empirical analyses on the transitory and long-run effects of sovereign ratings information on emerging stock and bond market interdependence with their respective regional indices.

We report a number of findings that add fresh insights to the literature. First, we find that whilst sovereign ratings provided by external rating agencies like Standard and Poors (S\&P) significantly influence emerging stock and bond market co-movements with their respective regional indices in the long-run, there is little evidence of destabilizing effects imparted across the board in the short-run. We report a heterogeneous response between stock and bond markets to sovereign credit ratings information.

Second, there is mostly a positive association between sovereign ratings and outlooks and regional stock return co-movements. This suggests that equity investors consider 'good news' relating to an individual country as providing a common positive regional investment climate 
leading to beneficial investment flows to other countries in the region and hence, higher positive return correlations. However, 'bad news' is regarded as country-specific assessments and investors react by shifting funds from the downgraded market into the surrounding region leading to a lower return correlation.

Third, in contrast to the stock market investigation results, we find there are relatively more negative relationships between outlooks and regional bond market co-movements. This indicates that when ratings and outlooks are downgraded, bond investors in the country may be inclined to withdraw funds from the surrounding markets in the region as well as from the downgraded bond market itself causing its regional market co-movement to rise. However, upgrades are seen as country-specific credit condition improvements drawing inflows from surrounding markets and hence, lowering intra-regional correlations. Good public debt management and economic strength appears to make a difference in the effects of sovereign ratings information across countries. We argue that the differential relationship between sovereign credit rating downgrades and intra-regional return correlations in stock and bond markets is largely due to a common lender effect in debt markets.

These results hold important implications for international portfolio investors and market regulators alike. For those countries with differential credit conditions to their regional counterparts, we reveal a decoupling-recoupling effect from their rating events. Rating upgrades are viewed as country-specific news that cause these countries to decouple from their own region whilst downgrades work to recouple the countries with their neighboring countries.

Overall, we contribute a new regional perspective to the literature on the financial market impacts of sovereign ratings by comprehensively examining both the permanent and transitory effects on asset return correlations and we distinguish the effects for stock vs. bond markets. This is an important contribution to current knowledge as financial crises tend to be regional in nature (case in point being the Asian Financial Crisis, Argentine debt crisis and most recently, the European debt crisis) so understanding the effect of ratings activity on intra-regional asset 
comovements over not only the short but also long-term enables improved guidance for policy makers and investors in mitigating the amplification of present and future financial crises. Our finding of a largely positive impact of sovereign ratings information on stock market comovements and an opposing negative influence on bond market comovements has very important policy implications in terms of how policy makers would need to design different policies to improve regional integration in the two types of financial markets. Fundamental changes in the credit quality of sovereign nations do not have the same integrative forces for stock and bond markets within the same region. Furthermore, our finding that higher rated countries have a tendency to decouple from the regional bond markets would have important policy implications considering the current sovereign debt crisis in Europe. That is, those with below average ratings in the region would experience higher intra-regional correlations as their ratings are cut, whereas those with above average ratings would decouple from the region as their ratings improve.

The rest of this paper is organized as follows. Section 2 outlines the data that will be used in our analyses. Section 3 will present the approach used to generate and model the various asset co-movements for the emerging markets in our sample. In Section 4 we discuss the results of our main analysis. Lastly, in Section 5 we conclude this paper by summarizing our main findings and we highlight their implications.

\section{Data description}

\subsection{Daily sovereign stock and bond market returns}

To generate the set of time-varying asset co-movements in our study we amalgamate a dataset comprising local currency closing prices of national stock and bond market indices for 19 and 15 emerging countries, respectively, as well as their corresponding regional market indices. ${ }^{2}$ Each

\footnotetext{
${ }^{2}$ Instead of constructing custom regional indices for each of the countries (regional index ex-the country under consideration), we utilize overall regional indices due to data limitation. This may introduce a slight positive bias to the correlation measures for some countries that have significant weight in their respective regional indices but better represent the relationship between countries and their geographical regions.
} 
emerging market can be classified into one of the following four regional groupings: Asia (8 stock markets, 6 bond markets), Europe (5,5) Latin America (4,2), and Middle East/Africa $(2,2){ }^{3}$ We observe three criteria that must be met by these emerging nations to be included in our dataset: Each country must i) be identified as 'emerging' according to www.securities.com (a Euromoney website) or www.ifc.com (the International Finance Corporation), following Gande and Parsley (2005)'s sample selection of international debt markets; ii) have either national stock and/or bond market index data available over the sample period ${ }^{4}$, iii) have experienced sovereign credit rating revisions by Standard and Poor's (S\&P) during the sample period. The geographical distribution of our sample coverage is summarized in Table 1.

[Insert Table 1 here]

The data covers the period from 1 January 1994 to 1 July 2007 yielding a maximum 3,524 daily return observations. The sample period is chosen to encompass the range of financial crises that dominated the 1990s, including the Asian Financial Crisis (1997-98), Russian Debt Default (1998), the Brazilian Crisis (1999) and the Argentine Crisis (2001-2002). These events triggered numerous sovereign ratings downgrades and volatile capital flows. Hence, their inclusion within the sample period serves to provide a richer dataset and allows a deeper analysis of sovereign ratings effects on emerging countries' stock and bond market return co-movements with their respective regional indices.

Consistent with Kaminsky and Schmukler (2002), we use the JP Morgan compiled ELMI and ELMI+ national bond indices which are designed specifically for emerging debt markets. The ELMI indices track local currency denominated short- and long-term debt total returns for a number of emerging markets. The ELMI+ expands on the ELMI series by including money

\footnotetext{
${ }^{3}$ The number of countries belonging to each region is displayed in brackets. Table 1 shows the full list of countries studied.

${ }^{4}$ In some cases, countries do not have data covering the whole sample period. We still include these countries in our sample when only a short period (ie. less than 3 years) of data was missing.
} 
market debt instruments from a wider variety of emerging markets. For national stock market data we employ market index from Datastream. We use daily index returns to accurately capture asset co-movements at a higher frequency as in studies like Kim et al. (2006).

Preliminary statistical analyses confirms that our returns data exhibit the documented characteristics of stock and bond index returns found in the literature (see Kim et al., 2006; Scruggs and Glabadanidis, 2003). As such, it is imperative to use a suitable model that will take into account these characteristics when generating the individual country's time-varying stock and bond market correlations with their respective regional indices.

\subsection{Sovereign ratings variables}

We employ historical S\&P long term sovereign ratings and outlook assessments for both local and foreign currency denominated debt to generate the independent variables to be used in our regression analyses. Outlooks differ from actual ratings as they are assessments on the potential changes in the direction of a credit rating in the intermediate term (typically over the next six months to two years). ${ }^{5}$ Whilst Brooks et al. (2004) note that there is not a $100 \%$ correspondence between local or foreign currency ratings, a change in one still triggers a change in the other $75 \%$ of the time. They find that foreign currency ratings consistently have greater market impact on asset returns. Moreover, as in Ferreira and Gama (2007), Gande and Parsley (2005) we utilize S\&P's sovereign ratings because S\&P is known to be the most active credit rating agency in making credit rating changes. Also, S\&P's rating decisions often elicit stronger market reactions indicating their rating revisions contain more information than those of other rating agencies. Finally, Gande and Parsley (2005) state that S\&P ratings precede Moody's ratings roughly twothirds of the time.

S\&P's ratings scale ranges from AAA (highest credit quality) to D/SD (default/selective default) and the outlooks attached to each credit rating can be positive, stable or negative. Similar

\footnotetext{
${ }^{5}$ See the S\&P's Website for a detailed definition

http://www2.standardandpoors.com/portal/site/sp/en/la/page.article/2,1,8,0,1148447709639.html
} 
to Cantor and Packer (1996), Ferreira and Gama (2007) and Gande and Parsley (2005), we use a standard linear rating transformation to produce a ratings time series for each country but unlike these studies, we do not amalgamate both ratings and outlook information. Separate daily rating (and outlook) time series for a particular country are generated by assigning the appropriate numerical value of a particular rating (outlook) on and after the day that it is implemented up until any subsequent revision is made. For example, Argentina's long-term foreign currency rating was changed from $\mathrm{CCC}+$ with negative outlook to $\mathrm{CC}$ with negative outlook on 30 October 2001, and then to SD on 6 November 2001. We assign the value of 1 for the days between 30 October 2001 and 5 November 2001, and 0 (the value for SD) for 6 November 2001 and beyond. As a result, four time series are generated for each country: foreign currency denominated debt ratings and outlook time series, and local currency denominated debt ratings and outlook series. Panels A and B of Table 2 describe the sovereign ratings and outlooks for foreign and local currency denominated debt in our sample, respectively. Across ratings and outlooks, the emerging markets in our sample receive more foreign than local currency denominated debt ratings revisions. Also, the number of outlooks and ratings are similar in terms of upgrades but there appears to be a bias in the outlook downgrades suggesting that negative outlooks are used more frequently to forewarn market participants of a sovereign obligor's imminent rating downgrade. Of all the regions, Asia has the greatest number of ratings and outlook revisions. This is because the Asian region contains a larger number of and more disparate 'emerging' countries than the other geographical regions, plus the sample period includes the tumultuous Asian Financial Crisis which led to a spate of credit ratings and outlook revisions for nearly all Asian countries.

[Insert Table 2 here]

\section{Empirical modelling}




\subsection{Modelling asset co-movements}

The first step in our analysis is to generate time-varying individual country stock and bond market correlations with their respective regional indices. We employ a bivariate $\operatorname{GARCH}(1,1)$ model with Engle's (2002) three-stage dynamic conditional correlation (DCC) estimation methodology. This procedure allows us to examine the structure of covariances (and hence, correlations) amongst various asset returns as well as the interactions between variances and covariances of these series. We calculate the correlations between national and regional market indices of stock and bond markets. The conditional mean equations are shown as below.

$$
\begin{gathered}
r_{i, t}=\alpha_{i}+e_{i, t} \\
r_{j, t}=\alpha_{j}+e_{j, t} \\
\boldsymbol{e}_{t}=\left[\begin{array}{l}
e_{i, t} \\
e_{j, t}
\end{array}\right] \sim N\left(0, H_{t}\right), H_{t}=\left[\begin{array}{ll}
h_{i i, t} & h_{i j, t} \\
h_{j i, t} & h_{j j, t}
\end{array}\right]
\end{gathered}
$$

The $r_{i, t}$ and $r_{j, t}$ are stock or bond index returns where the subscripts $i$ and $j$ refer to national and regional market index returns, respectively. The error terms are $e_{i, t}$ and $e_{j, t}$, respectively. We assume these error terms follow a conditional multivariate normal distribution with zero mean and variance-covariance matrix $H_{t}$. The formulation for the covariance matrix $H_{t}$ is given by the following specification:

$$
\begin{gathered}
h_{i i, t}=\beta_{c, i i}+\beta_{a, i i} \cdot e_{i i, t-1}^{2}+\beta_{b, i i} h_{i i},_{t-1} \\
h_{j j, t}=\beta_{c, j j}+\beta_{a, j j} \cdot e_{j j, t-1}^{2}+\beta_{b, j j} h_{j j},_{t-1} \\
h_{i j, t}=\beta_{c, i j}+\beta_{a, i j} \cdot e_{i i, t-1} \cdot e_{i j t-1}+\beta_{b, i j} h_{i j},_{t-1}
\end{gathered}
$$

The time varying conditional correlations are calculated as below: 


$$
\rho_{i j, t}=h_{i j, t} / \sqrt{h_{i i, t} \cdot h_{j j, t}}
$$

This procedure yields the time-varying asset return correlations for each emerging market and its regional market over the sample period. These dynamical conditional correlations (DCCs) will be used as dependent variables in the estimations discussed in the next section. ${ }^{6}$

\subsection{Sovereign ratings effects on asset co-movements}

We aim to explain the time-varying nature of the conditional correlations that may exist due to economic and financial market developments. ${ }^{7}$ Hence, we model daily asset return co-movements (in separate country regressions) as a function of sovereign rating and outlook levels using an error correction model (ECM). Through this formulation we are essentially asking the question: How do sovereign ratings affect an emerging market's stock and bond market interdependence with its own region in both the short- and long-term? The literature is missing such a comprehensive study of an emerging market's regional financial interdependence. We move away from the traditional panel and event study methodologies used to measure the influence of sovereign ratings (see Brooks et al. 2004; Ferreira and Gama, 2007; Kaminsky and Schmukler, 2002) and conduct our investigation using ECMs to capture the transitory and permanent effects of rating and outlook revisions on estimated DCCs. To implement this, we simultaneously estimate the cointegrating equation and the ECM model represented below ${ }^{8}{ }^{9}$ :

\footnotetext{
${ }^{6}$ The estimated time-varying correlations, $\rho_{i j, t}$ are insensitive to the functional form of the bivariate GARCH model employed including varied autoregressive and moving average lag structures in the conditional mean equations as well as to alternative estimation methodologies such as BEKK methods.

${ }^{7}$ The DCC's we estimated reveal a number of important results. First, in general, we observe that in both stock and bond market co-movements, significant structural breaks exist - regional market interdependencies fall and then recover. These structural breaks tend to be around financial crises unique to each region. Second, for bond markets, these structural breaks tend to arrive one or two years later than in the stock markets consistent with a flight-to-safety story. That is, the timing suggests that the bond markets were, in general, less affected during the heights of financial crisis periods as they benefited from domestic investors fleeing from severe downturns in their domestic stock markets. The graphs for the estimated DCC's for all the countries' stock and bond markets are available upon request.

${ }^{8}$ Augmented Dickey Fuller (ADF) tests were conducted on all the variables in our analyses in both levels and first differences for up to lag 5 (one week). While the estimated DCCs are stationary in all cases, the coefficient on the AR(1) coefficient is close to unity in nearly all cases for the bond DCCs and in most cases for the stock DCCs. In addition, we find that both the rating and outlook variables are non-stationary and I(1) in all cases. The control
} 


$$
\begin{gathered}
\operatorname{DCC}_{i j, t}=\alpha_{0 i}+\alpha_{1 i} \text { Rating }_{i, t}+\alpha_{2 i} \text { Outlook }_{i, t}+\varepsilon_{i, t} \\
\Delta D C C_{i j, t}=\beta_{0 i}+\beta_{1 i} \text { ARating }_{i, t}+\beta_{2 i} \text { OOutlook }_{i, t}+\beta_{3 i} \varepsilon_{i, t-1}+\beta_{4 i} \text { FXVOL }_{i, t}+\beta_{5 i} V I X_{i, t}+u_{i, t}
\end{gathered}
$$

Where

$$
\begin{aligned}
& D C C_{i j, t}=\begin{array}{l}
\text { Dynamic Conditional Correlations of country } i \text { at time } t \text { with its regional index } j \\
\text { (for stock and bond markets estimated separately). }
\end{array} \\
& \text { Rating }_{i, t}=\left\{\text { FCRating }_{i, t}, \text { LCRating }_{i, t}\right\} \text { are the foreign currency and local currency } \\
& \text { sovereign credit ratings for country } i \text { at time } t \text {, respectively. } \\
& \text { Outlook }_{i, t}=\left\{\text { FCOutlook }_{i, t}, \text { LCOutlook }_{i, t}\right\} \text { are the foreign currency and local currency } \\
& \text { sovereign credit outlooks for country } i \text { at time } t \text {, respectively. } \\
& F X V l_{i, t}=\text { Exchange rate volatility of country } i \text { at time } t \text { given by the square of exchange rate } \\
& \text { return over } \mathrm{t}-1 \text { and } t \text {. The exchange rate of country } i \text { is against the USD at time } t \\
& V I X_{i, t}=\text { CBOE's Volatility Index (VIX) of country } i \text { at time } t .
\end{aligned}
$$

Due to limited data availability at the daily frequency for economic control variables (e.g. GDP growth is reported quarterly), we include only two control variables that have gained prominence in the asset co-movement literature. Connolly et al. (2005) report that some measures of stock market uncertainty are useful in explaining intra-country stock and bond market comovements. In line with their work, we employ the Chicago Board of Option Exchange (CBOE)'s Volatility Index (VIX) as a proxy for financial and economic uncertainty. As the VIX represents a global factor capturing international investors' risk aversion, we expect a priori for it to have a positive effect on intra-regional asset correlations. The other control measure we employ is exchange rate volatility proxied by the squared daily exchange rate returns. FXVol is expected to dampen the extent of co-movement between markets (see Bracker et al., 1999 and Bodart and Reding, 1999).

variables we use, FX volatilities (FXVOL) and the VIX are both stationary. Similar but weaker results are obtained using local currency sovereign ratings. We do not report these summary statistics and local currency rating ECM model estimations to save space. However, interested readers may obtain these results from the corresponding author upon request.

${ }_{9}^{9}$ In model 4, we specify a unidirectional causality running from Ratings and Outlooks to DCC. In Appendix A and B we report Granger Causality test estimations. For both equity and bond market correlations, the direction of Granger causality is from the Ratings/outlooks to the DCCs. The reverse causality is not found to be significant in any case. Therefore the causal flow from the Ratings/outlook to DCCs as specified in model (4) is appropriate. 
We expect that the coefficients for the long-run ratings and outlook parameters, $\alpha_{1}$ and $\alpha_{2}$ and the short-term effects $\beta_{1}$ and $\beta_{2}$, can be either positive or negative as Gande and Parsley (2005) suggest that there could be common or differential information spillover effects from sovereign rating events. The positive coefficient signifies that an upgrade (downgrade) in rating and/or outlook results in an increase (decrease) in stock and bond market co-movements with their respective regional indices. A plausible explanation for this may be that an increase in ratings/outlook has a common information effect and encourages outside foreign investors to invest funds in the country receiving the upgrade as well as in surrounding countries leading to an incremental rise in a country's inta-regional market co-movements. A downgrade would have an opposite impact. On the other hand, a negative coefficient indicates that an upgrade (downgrade) in rating and/or outlook results in a decrease (increase) in the co-movements. This would be the case if the ratings change is specific to the country involved and so does not convey the general change in credit quality of the region as a whole. Thus, this might suggest the possibility of investors shifting funds into upgraded countries from surrounding nations, all things being equal, causing a reduction in their correlations with the rest of the region. In the event of a downgrade, it can be argued that contagion effects will lead investors to shift funds out of the emerging market experiencing the downgrade as well as its surrounding countries. This would then reinforce a positive intra-regional return correlation. This contagion effect during downgrade cycles is well documented in the literature (see Calvo, 1996; Ferreira and Gama; 2007; Gande and Parsley, 2005; Kaminsky and Schmukler; 2002). We also conjecture that the ratings and outlook coefficients for the bond market estimations will be of greater magnitude since sovereign ratings and outlooks are designed to be credit assessments specifically for fixed income markets and should have both greater informational value than in stock markets in the short-term and a stronger equilibrium relationship with asset co-movements in the long-run.

\section{Empirical results}




\subsection{Impacts of sovereign ratings on regional interdependence}

Tables 3 and 4 report the ECM estimation results for stock and bond market DCCs with their respective regional indices. ${ }^{10}$ Across the two classes of asset correlations, what is most striking is that there is a strong and pervasive long-term relationship with sovereign ratings and outlooks (significant $\alpha_{1}$ and $\alpha_{2}$ ) but the transitory effects of rating and outlook $\left(\beta_{1}\right.$ and $\beta_{2}$ ) appear significant only for a handful of countries. The coefficients for both outlooks $\left(\alpha_{2}\right)$ and ratings $\left(\alpha_{1}\right)$ in the cointegrating equation and as represented by the error-correction term $\left(\beta_{3}\right)$ are highly significant for both stock and bond market co-movements. The error correction term $\left(\beta_{3}\right)$ is negative and significant in all the estimations suggesting that unexpected deviations from the long-run relationship are being corrected. This suggests that sovereign ratings as well as outlooks convey useful information regarding the long-term risk levels of sovereign government bonds and stock market investments. What is also important to note is that in the long-run, ratings are relatively more important than outlooks but in the short-term outlooks present a more significant effect (i.e. magnitude of $\beta_{2}$ being generally larger that $\beta_{1}$ ) on intra-regional market correlations, especially in the case of emerging bond markets reported in Table 4, consistent with Pukthuanthong-Le et al.'s (2003) comparison of the contemporaneous impacts of sovereign rating announcements in stock and bond markets. In their emerging market analysis, Kaminsky and Schmukler (2002) find that outlooks have a significant and immediate impact on sovereign stock and bond returns implying that the informational effects of ratings may be diminished as outlooks present an earlier insight into the creditworthiness of a country and the latest assessment of developments in its sovereign debt market. In the event of upgrades, national governments also have an incentive to leak rating changes before they are made public so rating changes have less market impact in the short-term. Similarly, in examining corporate credit default swap (CDS)

\footnotetext{
${ }^{10}$ Estimation results for both foreign and local currency denominated debt ratings and outlooks are qualitatively the same so we have omitted the local currency rating results for brevity. These are available upon request. It should be noted that bond market correlations were relatively more sensitive to local currency ratings as market indices used comprised a large proportion of local currency denominated debt instruments. Notwithstanding this, consistent with Brooks et al. (2004) we find that foreign currency ratings were relatively more significant than local currency ratings.
} 
spreads, Micu et al. (2006) argue that outlooks are less likely to be anticipated by financial market participants as they forewarn investors of possible ratings changes. Credit ratings, on the other hand, signal a permanent and fundamental change in issuers' creditworthiness reflecting information which may already be publicly available to market participants at the time of revision. It has also turned into common practice for rating agencies to communicate any imminent rating changes (especially downgrades) well in advance so as not to unduly surprise financial market participants.

The two control variables, exchange rate volatility (FXVOL) and the VIX index show mixed influences on both the stock and bond market correlations. Positive and negative influences are relatively evenly spread across the countries for both sets of estimations.

[Insert Tables 3 and 4 here]

\subsection{Impacts of sovereign ratings on regional stock market interdependence}

The stock market ECM estimations are reported in Table 3. We find a highly significant relationship between ratings/outlooks and stock market co-movements in the long-run. The longrun coefficients on ratings and outlooks $\left(\alpha_{1}\right.$ and $\left.\alpha_{2}\right)$ are mostly significant and positive (14 positive vs. 4 negative for ratings, 8 positive vs. 2 negative for outlooks). The positive coefficients suggest that as credit conditions of individual countries (as proxied by sovereign ratings and outlooks) improve, their return correlations with the aggregate region rise. This is consistent with the view that investors may interpret upgrades in credit quality not only as a sign of better stock market prospects in the country that experiences this upgrade but also extrapolate this information to apply to its surrounding region (see Gande and Parsley, 2005; Ferreira and Gama; 2007). Gande and Parsley (2005) term this as 'common information spillovers' from sovereign rating events. This would be the case especially if the country involved is regarded as representing the region and so foreign investors use its credit conditions to judge the investment 
climates not only for that country alone but also the neighboring region as a whole to some extent. Therefore, foreign investors are encouraged to also invest in surrounding markets causing the composite regional stock market index to also rise. In the case of rating downgrades, however, this positive correlation falls. This might suggest that international investors view the rating events as country specific news and re-allocate funds within the region in favor of other countries in the region. In both instances, there appears to be a positive rating spillover effect for the region as a whole providing long-term financial stability for emerging market regions. These results provide further evidence to corroborate with studies such as Brooks et al. (2004), Chiang et al. (2007), Ferreira and Gama (2007) and Kaminsky and Schmukler $(1999,2002)$ in that sovereign credit ratings and outlooks have informational content that can significantly influence international stock market returns and as we document in this study, also intra-regional return correlations. $^{11}$

Against this trend, there are significant and negative long-run effects of sovereign ratings for the Philippines, Taiwan, Czech Republic and Turkey. Similarly, the long run outlook coefficients are also significant and negative for India and Israel. We conjecture that rating and outlook downgrades will continue to discourage investment in these countries' and their neighboring stock markets for some time after a revision due to their past debt history (and debt burden). This is because these countries have at some stage, either borrowed from the International Monetary Fund (e.g., Argentina, India, the Philippines, Turkey), relied on shortterm debt (e.g., Turkey), experienced high inflation levels or have large amounts of debt outstanding (e.g., India and Turkey). ${ }^{12}$ An alternative explanation for the opposing responses for

\footnotetext{
${ }^{11}$ According to Ferreira and Gama (2007) there are three reasons why the stock market should be expected to react to a sovereign ratings downgrade. Firstly, a downgrade can influence a country's ability to borrow in international markets which can contribute to a credit crunch and lead to a negative impact on the stock market. Secondly, governments can take actions when ratings are downgraded, such as raising corporate taxes (to compensate for increased costs of debt service), which can affect companies' future prospects (ie. cash flows). Thirdly, restrictions on institutional investors like pension funds to only be able to hold investment grade instruments implies that ratings downgrades can have a negative impact on security prices.

${ }^{12}$ Comparisons were made using figures on IMF credits used, amounts of debts rescheduled, ratio of short term debt to total external debt, inflation, and value of total external debt from the World Bank's World Development
} 
the four countries is that their credit conditions as represented by foreign currency ratings and outlooks are not representative of those for their respective regions. Indeed, we find the countries with negative coefficients tend to have rating positions above their regional cohorts so when their ratings improve, they further differentiate their credit quality from their regional counterparts (see Table 1). Thus, foreign capital inflows into the ratings upgraded countries may crowd out those going into the other countries in their respective regions. However, downgrades for these countries still pose major signals of deterioration for their neighboring regions due to their chequered debt histories and can sufficiently change investor sentiment to steer away from the aggregate region. The last column of Table 3 reports individual country's ratings correlation with their region. The countries with a negative ratings coefficient all have either negative correlation with their regional average (the Philippines, -0.6724) or considerably low positive correlation compared to the other countries in their region (Taiwan, 0.1639; Czech Republic, 0.0614; Turkey, 0.3697). Negative or low positive correlations of ratings would suggest that ratings improvements in these countries are mostly country specific and so crowd out foreign capital flows to the other countries in the region. It appears that lower rating correlations suggest that these markets' long term credit conditions are largely independent of regional developments and so their ratings movements are taken to be country specific information rather than conveying region wide information. We term this as the 'decoupling-recoupling effect' as a country-specific upward revision in ratings and/or outlooks essentially works to decouple these emerging markets from their regional counterparts whilst a downward rating revision exerts a common signal that pulls them back in line (creating the recoupling effect). This is also consistent with Gande and Parsley's (2005) view on differential and common information spillovers in international debt markets from rating events.

The short-term effects of ratings and outlooks (where significant) are all in the opposite direction to the long-run effects. The significant short-term coefficients for rating and/or outlook

Indicators. However, data was not available for all countries making it invalid to use these as potential interactive conditions in regression analyses. 
revisions in Malaysia and Israel are negative suggesting that investors are particularly sensitive to the short-term credit guidance of politically unstable, war or terrorism prone countries. Earlier studies that focused on assessing the short-term market impact of sovereign ratings information mask the discerning impacts in the short-term as revealed by our error correction model.

\subsection{Impacts of sovereign ratings on regional bond market interdependence}

Table 4 shows the ECM estimation results for bond market DCCs. In general, we observe an opposite pattern of responses compared to the stock market responses. First, we note that the significant coefficients for both the ratings and outlooks are larger in magnitude than comparable ones for the stock market estimations indicating that sovereign credit ratings have greater economic significance for debt than stock markets - in general, by a factor of 10 or more (e.g. for Hong Kong, a one notch ratings move will change intra-regional correlations by 0.0006 and 0.0437 for stock and bond markets, respectively). As we explained above, due to the direct impact ratings information would have on fixed income markets, we expected more influence in bond than in stock markets. Second, unlike stock market correlations, the long-run coefficients on ratings and outlooks are mostly significant and negative ( 5 positive vs. 8 negative for ratings, 2 positive vs. 5 negative for outlooks). Ratings improvements are associated with declining bond market correlations in general which suggests that these events are country-specific and lead to lower correlations as capital flows to the ratings upgraded country might be at the expense of the surrounding country bond markets.

We find that the countries that have ratings higher than their regional average rating tend to have a negative ratings coefficient. Out of the eight countries that have a negative ratings coefficient in the long run equation, six have higher ratings than their regional average. We conjecture that higher rated countries would tend to decouple from other countries in the region as their ratings improve. 
On the other hand, deteriorations in ratings and outlooks are typically associated with higher perceived default risk due to a general deterioration in political, financial and/or other factors pertaining to the rated country, which often lead investors of emerging markets to infer similar permanent declines of credit quality in surrounding nations. Therefore, investors are likely to withdraw funds from the surrounding region as well as the downgraded country contributing to drastic regional contagion effects. Furthermore, this result is substantiated by the fact that it is during prolonged periods of financial distress that credit rating agencies are most active in issuing rating and outlook downgrades. Existing studies also provide empirical evidence of these negative rating spillover effects when sovereign rating/outlook downgrades are issued (see Gande and Parsley, 2005; Kaminsky and Schmukler, 2002). As explained by Kraussl (2003), Bekaert and Harvey (2003) and Calvo (1996), contagion effects can occur in developing countries because it is generally too costly for investors in emerging markets to carry out comprehensive country-specific analyses. Therefore, they will consider several markets in the same region to be substantially homogeneous, preferring to herd and follow a handful of informed investors or information intermediaries like financial analysts (or in our case, external rating agencies). Gande and Parsley (2005) call this a common information spillover effect and in their study of bond spreads, find a clear predominance of its influence on spreads in nearby countries in the case of rating downgrades, but without such discernable evidence in the case of upgrades, which are viewed as country-specific improvements in domestic investment conditions. Putting all existing evidence together, we argue that the fundamental difference in the relationship between bond and stock market correlations with sovereign credit ratings, is the existence of the common lender effect in debt markets (as documented in Van Rijckeghem and Weder, 2003). Competition in credit markets and common creditors have been identified as a key channel through which financial crises are spread. It is conceivable that when a lender faces an increasing proportion of non-performing loans in a downgraded country, it is forced to curb its lending to other countries 
in the region, leading to a significant shortage of credit supply in neighboring countries that rely on the same lender and hence, increasing bond market return correlations within the region.

Yet our cross-country analyses reveals that not all emerging bond markets are vulnerable - in the case of the 5 countries with non-negative rating coefficients in the long-run, Hong Kong, the Philippines, Slovenia, Turkey and South Africa, and the 2 countries that have a positive outlook coefficient, Greece and Israel, investors appear to infer that downgrades in these relatively strong emerging countries' ratings are specific to their domestic developments (typically arising from political risks) and they do not apply to fundamental deteriorations in investment conditions within their respective regions. These countries all enjoyed significant capital investment growth and engaged in much trade activities relative to GDP over our sample period. ${ }^{13}$ For the 3 countries out of 5 that show positive ratings coefficients, it appears that low or negative ratings correlation might also be responsible. Hong Kong and the Philippines show negative ratings correlation with the Asian region and Turkey has the second lowest rating correlation with the emerging European region.

In contrast, the short-term effects of outlook changes work in the opposite direction to the long-run effects, again reaffirming how important it is to differentiate between the long-run and transitory effects of sovereign ratings information on asset correlations. The short-term rating impacts are mostly positive but only the negative coefficients for Taiwan and South Africa are significant. We conjecture that these two economies' political tensions are weighing on investor confidence regarding surrounding countries. There are positive short-term influences of outlooks on the bond market interdependencies of Hong Kong, Slovenia and Turkey and this is consistent with Kaminsky and Schmukler's (2002) revelation of outlooks' dominant effects over actual ratings changes immediately after revisions. For all other bond markets there are no short-term effects imparted by ratings and outlook revisions. This implies that improvements in outlooks for

\footnotetext{
${ }^{13}$ Comparisons are made based on growth in gross fixed capital formation and total value of trade (imports and exports) relative to GDP sourced from the World Bank's World Development Indicators dataset. However, figures were not available for all these countries.
} 
Hong Kong, Turkey and Slovenia are associated with higher bond market correlations in the short-term, consistent with a view that improvements in outlooks are treated by bond investors in these 3 countries as clear signals of financial strength and investors become more confident in increasing their portfolio allocations to neighboring countries within the Asia Pacific, Emerging Europe and Middle East regions as well. Specifically, a revaluation of the future credit quality of these sovereign obligors may lead investors to infer similar improvements for bond markets in neigboring nations within the same region. Hence, investors may be immediately induced to shift funds into bond markets with improved outlooks as well as into countries in the surrounding region.

In sum, we find that bond markets experience negative regional rating spillover effects and the financial impacts are on a larger scale since sovereign ratings/outlooks are designed as credit assessments specifically for debt markets ${ }^{14}$. We find that whilst sovereign ratings also have informational value in stock markets, they instead impart a positive regional rating spillover effect. Emerging market participants and policy makers need to be aware that rating and outlook downgrades have significant impacts in emerging debt markets and work to increase financial instabilities and retard regional financial developments whereas downward revisions in sovereign ratings. On the other hand, outlooks may actually be beneficial for stock market integration at a regional level as investment funds are re-distributed to surrounding countries and contained within the region. Thus, rating agencies need to monitor developments in the countries they are rating and revise as necessary in a timely manner so as not to exacerbate the procyclical effects of sovereign ratings in international financial markets. We contribute a new regional perspective to

\footnotetext{
${ }^{14}$ In unreported estimations, we also controlled for the influence of sovereign obligors' debt exposures and the degree of financial market openness in modelling the relationship between ratings/outlook and DCCs. We added appropriate controls for each category, both in terms of a representative variable in each category (central government debt per GDP and net financial inflows per GDP sourced from the World Bank's World Development Indicators database) and by using two principal components generated from a wide list of variables in each category in equation (4). The results of these additional control estimations do not significantly differ from the results we report in Tables 3 and 4 in this paper. They have been omitted for brevity but are available upon request. We find, however, that, those countries with a negative ratings coefficient tend to have an above (regional) average credit rating and this suggests that higher rated countries tend to become more isolated from its region after a ratings upgrade.
} 
the literature on the financial market impacts of sovereign ratings by examining both the permanent and transitory effects on return correlations in emerging stock and bond markets.

\section{Conclusion}

Sovereign credit ratings have become an integral part of macroprudential regulation and internal industry guidelines and as such plays a pivotal role for emerging market investments. Research over the last decade has confirmed this fact by providing strong empirical evidence indicating sovereign ratings serve the function of enhancing the transparency of an emerging market's credit risk profile and therefore can significantly influence its national stock and bond market investment flows. However, while the impacts of these credit assessments on stock and bond markets have been identified, there is a lack of understanding on their specific role on the interdependencies between financial markets. Given the apparent linkages in stock and bond investment flows across national markets from the same region, most evidently during the numerous financial crises of the 1990s and early 2000s, it is surprising that a thorough investigation on the role of sovereign ratings in determining these asset co-movements is missing from the current literature.

The primary objective of this paper has been to address this particular oversight in the literature. Specifically, we conduct various analyses to measure the impact of sovereign ratings on an emerging market's: 1) stock market co-movement with its corresponding regional stock market index, and 2) bond market co-movement with its corresponding regional bond market index. We find heterogeneous rating spillover effects in these two key asset markets. The major results of this paper are as follows.

First, we report a fundamental difference in the effects of sovereign ratings information on both stock and bond market interdependence over different time-frames. Asset correlations are much more strongly linked to ratings and outlooks in the long-run than in the short-run. 
Second, in the long-run we observe predominantly positive regional rating spillover effects of sovereign ratings and outlooks onto stock market co-movements. This implies that ratings and outlook improvements lead to higher returns not only in the affected country but also in the countries surrounding it. This is the case if foreign investors view the stock markets in a region as having common characteristics. On the other hand during the periods of downgrades, international equity investors tend to shift funds away from the affected stock market in favor of other stock markets in the region.

Third, we report a predominantly negative regional rating spillover effect of ratings and outlook onto bond market co-movements. This suggests that when ratings and outlooks are revised downwards, investors in the country may be inclined to withdraw funds from the surrounding regional markets as well as the downgraded market, causing its regional bond market co-movement to rise. However, when there is a sovereign credit improvement, international bond investors shift funds away from other bond markets in the region in favor of the affected market and this leads to a fall in regional correlations. In addition, we find the negative influence is concentrated in the countries that have higher foreign currency debt ratings than the regional average. This suggests that in better rated countries, bond markets tend to decouple from their regional counterparts when their ratings improve as investors react by concentrating their regional investments into these regional leaders. Consistent with existing ratings studies, we find that credit outlooks have greater market impact than actual ratings in the short-term. The differential response of bond market correlations to sovereign credit ratings is consistent with the existence of a common lender effect in debt markets during financial crises.

There are important implications for portfolio management in these findings as we reveal that stock and bond markets respond heterogeneously to sovereign ratings. We infer that downward rating and outlook revisions work to increase diversification potential in regional stock portfolios in emerging countries whilst outlook and rating downgrades serve to reduce diversification opportunities in regional bond portfolios. Importantly, we find that rating 
downgrades do enhance international bond market linkages and potentially fuel episodes of financial contagion. Thus, rating agencies need to monitor developments in the countries they are rating and revise as necessary in a timely manner so as not to exacerbate the pro-cyclical effects of sovereign ratings in international debt markets. As our empirical results strongly suggest that ratings information have primarily a long run impact on intra-regional asset correlations, we conjecture that the recent downgrades in sovereign ratings (for countries facing fiscal problems in Europe and even the United States in the fallout from the Global Financial Crisis) will cause the downgraded countries' stock markets to underperform and decouple from their regional counterparts for some time and the sovereign debt markets within an affected region will conversely become highly correlated as is the case in Europe presently. We contribute a new regional perspective to the literature on the financial market impacts of sovereign ratings by examining both the permanent and transitory effects on asset return correlations and identify clearly differential effects for stock and bond markets. However, we leave the exploration of rating spillover effects on asset correlations for further research." 


\section{References}

Baig, T., Goldfajn, I., 1999. Financial Market Contagion in the Asian Crisis. IMF Staff Papers, 46(2), 167-195. Washington, DC.

Bekaert, G., Harvey, C. R., 1995. Time-Varying World Market Integration. Journal of Finance $50,403-444$.

Bekaert, G., Harvey, C. R., 2003. Emerging Markets Finance. Journal of Empirical Finance 10, $3-55$.

Bekaert, G., Hodrick, R., Zhang, X., 2009. International stock return comovement. Journal of Finance 64, 2591-2626.

Bodart, V., Reding, P., 1999. Exchange Rate Regime, Volatility and International Correlations on Bond \& Stock Markets. Journal of International Money and Finance 18, 133-151.

Bracker, K., Docking, D. S., Koch, P. D., 1999. Economic Determinants of Evolution in International Stock Market Integration. Journal of Empirical Finance 6, 1-27.

Brooks, R., Faff, R. W., Hillier, D., Hillier, J., 2004. The National Market Impact of Sovereign Ratings Changes. Journal of Banking and Finance 28, 233-250.

Calvo, G., 1996. Capital Inflows and Macroeconomic Management: Tequila Lessons. International Journal of Finance and Economics 1, 207-223.

Cantor, R., Packer, F., 1996. Determinants and Impact of Sovereign Credit Ratings. Federal Reserve Bank of New York Economic Policy Review 2(2), 37-53.

Connolly, R., Stivers, C., Sun, L., 2005, Stock market uncertainty and the Stock-Bond Return Relation. Journal of Financial and Quantitative Analysis 40, 161-194.

Chiang, T.C., Jeon, B.N., Li, H., 2007. Dynamic correlation analysis of financial contagion:

Evidence from Asian markets, Journal of International Money and Finance 26, 12061228. 
Engle, R. 2002. Dynamic Conditional Correlation-A Simple Class of Multivariate GARCH Models. Journal of Business and Statistics 20, 339-350.

Ferreira, M. A., Gama, P. M., 2007. Does Sovereign Debt Ratings News Spill over to International Stock Markets? Journal of Banking and Finance 31, 3162-3182.

Gande, A., Parsley, D. C., 2005. News Spillovers in the Sovereign Debt Market. Journal of Financial Economics 75, 691-734.

Glick, R., Rose, A., 1999. Contagion and trade: why are currency crises regional Journal of International Money and Finance 18, 603-617.

Hernandez, L. F., Valdez, R. O., 2001. What Drives Contagion: Trade, Neighborhood, or Financial Links? IMF-Working Paper 01/29. Washington, DC.

Kaminsky, G. L., Reinhart, C. M., 1999. The twin crises: the causes of banking and balance of payments problems. American Economic Review 89, 473-500.

Kaminsky, G., Schmukler, S. L., 2002. Emerging Market Instability: Do Sovereign Ratings Affect Country Risk and Stock Returns? World Bank Economic Review 16(16), 171-195.

Kim, S.-J., Moshirian, F., Wu, E., 2006. Evolution of International Stock and Bond Market Integration: Influence of the European Monetary Union. Journal of Banking and Finance $30,1507-1534$.

Kim, S.-J., Wu, E., 2008. Sovereign credit ratings, capital flows and financial sector development in emerging markets, Emerging Markets Review, 9, 17-39.

Kraussl, R., 2005. Do credit rating agencies add to the dynamics of emerging market crises? Journal of Financial Stability 1, 355-385.

Micu, M., Remolona, E., Wooldridge, P., 2006. The price impact of rating announcements: which announcements matter? BIS working papers No. 207. Basel.

Pukthuanthong-Le, K., Elayan, F., Rose, L.C., 2007. Equity and debt market responses to sovereign credit rating announcements, Global Finance Journal 18, 47-83. 
Reinhart, C. M., Rogoff, K. S., 2004. Serial Default \& the 'Paradox' of Rich-to-Poor Capital Flows. American Economic Review 94, 53-58.

Reisen, H., von Maltzan, J., 1999. Boom and Bust and Sovereign Ratings. International Finance 2(3), 273-293.

Scruggs, J. T., Glabadanidis, P., 2003. Risk Premia and the Dynamic Covariance between Stock ad Bond Returns. Journal of Financial and Quantitative Analysis 38(2), 295-316.

Van Rijckeghem, C., Weder, B., 2003. Spillovers through banking centers: A panel data analysis of bank flows, Journal of International Money and Finance 22, 483-509. 


\section{Table 1. Geographic Distribution of Sample Countries}

This table presents the list of all the emerging markets used in this study. The number in the bracket after the name of a country represents the average numerica foreign currency rating level for the sample period and it ranges from 20 for AAA to 0 for SD/D ratings. Similarly, the number after the name of a region is the average rating of all the countries in that region for the sample used.

\begin{tabular}{|c|c|c|c|c|c|}
\hline & Stock market data & & & Bond market data & \\
\hline Region & Constituent Countries & $\begin{array}{l}\text { Total no. } \\
\text { countries }\end{array}$ & Region & Constituent Countries & $\begin{array}{l}\text { Total no. } \\
\text { countries }\end{array}$ \\
\hline Asia (12.50) & $\begin{array}{l}\text { Hong Kong (15.78), Indonesia (6.92), India } \\
\text { (9.64), Malaysia (13.77), The Philippines } \\
\text { (9.04), Korea (14.01), Taiwan (18.22), } \\
\text { Thailand (12.60) }\end{array}$ & 8 & Asia (12.76) & $\begin{array}{l}\text { Hong Kong (15.78), Indonesia (6.92), The } \\
\text { Philippines (9.04), Korea (14.01), Taiwan } \\
\text { (18.22), Thailand (12.60) }\end{array}$ & 6 \\
\hline Europe (10.65) & $\begin{array}{l}\text { Czech Republic (14.05), Greece (13.34), } \\
\text { Poland (11.81), Russia (7.40), Turkey (6.68) }\end{array}$ & 5 & Europe (11.43) & $\begin{array}{l}\text { Czech Republic (14.05), Greece (13.34), } \\
\text { Poland (11.81), Slovak Republic (11.30), } \\
\text { Turkey (6.68) }\end{array}$ & 5 \\
\hline Latin America (8.28) & $\begin{array}{l}\text { Argentina (6.75), Brazil (7.45), Mexico } \\
(10.20), \text { Peru (8.73) }\end{array}$ & 4 & Latin America (8.47) & Argentina (6.75), Mexico (10.20) & 2 \\
\hline Middle East \& Africa (12.36) & Israel (13.86), South Africa (10.86) & 2 & Middle East \& Africa (12.36) & Israel (13.86), South Africa (10.86) & 2 \\
\hline$\overline{\text { TOTAL }}$ & & 19 & TOTAL & & 15 \\
\hline
\end{tabular}


Table 2. Summary Description of Sovereign Ratings Events

This table presents the summary statistics of ratings and outlooks for our sample of emerging markets grouped according to region. Panels A and B summarize the foreign and local currency denominated sovereign credit ratings/outlook events, respectively.

\begin{tabular}{lccccc} 
& \multicolumn{3}{c}{ Outlooks } \\
\cline { 2 - 6 } & Uatings & & & \\
\hline Panel A: Foreign Currency Ratings & & & & & \\
\hline Asia & 30 & 26 & 1 & 34 & 121 \\
Latin America & 22 & 18 & 28 & 28 & 96 \\
Europe & 30 & 14 & 24 & 26 & 94 \\
Middle East and Africa & 5 & 0 & 4 & 5 & 14 \\
\hline Total & 87 & 58 & 87 & 93 & 325 \\
\hline Panel B: Local Currency Ratings & & & & & \\
\hline Asia & 17 & 22 & 24 & 25 & 88 \\
Latin America & 14 & 13 & 14 & 13 & 54 \\
Europe & 21 & 9 & 16 & 17 & 63 \\
Middle East and Africa & 3 & 1 & 4 & 4 & 12 \\
\hline Total & 55 & 45 & 58 & 59 & 217 \\
\hline
\end{tabular}




\section{Table 3. ECM Estimation Results: Sovereign rating and outlook effects on Stock market co-movements}

In this table, the estimates for stock market co-movements are shown. The ECM model estimated is defined in Eq. (4)

$$
\begin{aligned}
& \text { DCC }_{i j, t}=\alpha_{0 i}+\alpha_{1 i} \text { Rating }_{i, t}+\alpha_{2 i} \text { Outlook }_{i, t}+\varepsilon_{i, t} \\
& \Delta D C C_{i j, t}=\beta_{0 i}+\beta_{1 i} \text { ARating }_{i, t}+\beta_{2 i} \Delta \text { Outlook }_{i, t}+\beta_{3 i} \varepsilon_{i, t-1}+\beta_{4 i} \text { FXVOL }_{i, t}+\beta_{5 i} V_{I X}+u_{i, t}
\end{aligned}
$$

where the dependent variable is the estimated time-varying stock market correlation of country $i$ at time $t$ with its regional index, Rating $g_{i, t}=F C R a t i n g_{i, t}$ is the foreign currency sovereign credit ratings for country $i$ at time, Outlook $k_{i, t}=$ FCOutlook $_{i, t}$ is the foreign currency sovereign credit outlooks for country $i$ at time, $F X V V_{i, t}=$ exchange rate volatility of country $i$ at time $t$, and $V I X_{\mathrm{i}, \mathrm{t}}=\mathrm{CBO}$ 's Volatility Index (VIX) of country $i$ at time $t$.

Notes: P-values are shown in brackets and ****** denote significance at the $10 \%, 5 \%$ and $1 \%$ level, respectively. To allow for a meaningful comparison across estimations, results presented are for those sample countries for which we were able to obtain data to generate both stock and bond market regional co-movements. Coint-Test shows the unit root test statistic for $\varepsilon_{i, t}$ where the null is I(1) where significance suggests cointegration.

\begin{tabular}{|c|c|c|c|c|c|c|c|c|c|c|c|c|}
\hline & $\alpha_{0}$ & $\alpha_{1}$ & $\alpha_{2}$ & $\beta_{0}$ & $\beta_{1}$ & $\beta_{2}$ & $\beta_{3}$ & $\beta_{4}$ & $\beta_{5}$ & Coint-Test & Nobs & R_Rho \\
\hline \multicolumn{13}{|l|}{ ASIA } \\
\hline \multirow[t]{2}{*}{ HKG } & 0.0001 & $0.0006^{*}$ & $0.0650^{\text {*ope }}$ & $-0.8550^{* * k *}$ & 0.0010 & 0.0146 & $-0.0415^{* 0 k \pi}$ & $0.8613^{* 00 *}$ & $-0.0002^{* * * k}$ & $-5.81^{* 0 k \pi}$ & 3524 & -0.0222 \\
\hline & $\{0.9798\}$ & $\{0.0010\}$ & $\{0.0003\}$ & $\{0.0000\}$ & $\{0.9133\}$ & $\{0.3544\}$ & $\{0.0000\}$ & $\{0.0000\}$ & $\{0.0000\}$ & & & \\
\hline \multirow[t]{2}{*}{ IDO } & 0.0518 & -0.0010 & $0.0777^{* *}$ & 0.0067 & -0.0001 & -0.0152 & -0.0351 & -0.0061 & 0.0000 & $-7.75^{*}$ & 3524 & 0.9655 \\
\hline & $\{0.0000\}$ & $\{0.1489\}$ & $\{0.0114\}$ & $\{0.0000\}$ & $\{0.9646\}$ & $\{0.4275\}$ & $\{0.0000\}$ & $\{0.0000\}$ & $\{0.0041\}$ & & & \\
\hline \multirow[t]{2}{*}{ IND } & $0.1272^{\text {wak }}$ & $0.0038^{\text {*toke }}$ & $-0.0207^{\text {selok }}$ & $0.2488^{\text {sopes }}$ & -0.0097 & -0.0609 & $-1.2517^{\text {weter }}$ & $-0.3092^{\text {selek }}$ & $-0.0027^{\text {*ater }}$ & $-9.84^{*}$ & 3524 & 0.6698 \\
\hline & $\{0.0000\}$ & $\{0.0000\}$ & $\{0.0000\}$ & $\{0.0000\}$ & $\{0.7450\}$ & $\{0.4672\}$ & $\{0.0000\}$ & $\{0.0000\}$ & $\{0.0000\}$ & & & \\
\hline \multirow[t]{2}{*}{ MAL } & 0.0082 & $0.0002^{*}$ & 0.0230 & 0.0326 & -0.0005 & -0.0228 & -1.1539 & 0.0197 & -0.0015 & -7.98 & 3524 & 0.9320 \\
\hline & $\{0.0000\}$ & $\{0.0000\}$ & $\{0.0000\}$ & $\{0.0000\}$ & $\{0.9312\}$ & $\{0.3987\}$ & $\{0.0000\}$ & $\{0.0000\}$ & $\{0.0000\}$ & & & \\
\hline \multirow[t]{2}{*}{ PHI } & 0.2029 & $-0.0060^{* * * * *}$ & $0.0144^{\text {*iok }}$ & $0.0138^{* * * k}$ & -0.0002 & $0.0687^{* *}$ & $-0.5136^{\text {sele }}$ & -0.0503 & $-0.0005^{*}$ & $-8.86^{*+*}$ & 3524 & -0.6724 \\
\hline & $\{0.0000\}$ & $\{0.0000\}$ & $\{0.0000\}$ & $\{0.0000\}$ & $\{0.9971\}$ & $\{0.0208\}$ & $\{0.0000\}$ & $\{0.0000\}$ & $\{0.0000\}$ & & & \\
\hline \multirow[t]{2}{*}{ KOR } & $0.0283^{* * * *}$ & $0.0034^{\text {*ate }}$ & 0.0297 & $-0.0245^{* * * * *}$ & 0.0009 & -0.0018 & $-0.0249^{\text {*atek }}$ & $0.0245^{\text {stope }}$ & 0.0000 & $-6.95^{* * * *}$ & 3524 & 0.8626 \\
\hline & $\{0.0000\}$ & $\{0.0000\}$ & $\{0.3128\}$ & $\{0.0000\}$ & $\{0.3127\}$ & $\{0.9320\}$ & $\{0.0000\}$ & $\{0.0000\}$ & $\{0.6094\}$ & & & \\
\hline \multirow[t]{2}{*}{ TAI } & 0.5553 & -0.0069 & 0.0050 & 0.3210 & -0.0135 & 0.0003 & -0.3948 & -0.4584 & -0.0009 & $-13.56^{* * *}$ & 3524 & 0.1639 \\
\hline & $\{0.0000\}$ & $\{0.0000\}$ & $\{0.5085\}$ & $\{0.0000\}$ & $\{0.8927\}$ & $\{0.9984\}$ & $\{0.0000\}$ & $\{0.0000\}$ & $\{0.0000\}$ & & & \\
\hline \multirow[t]{2}{*}{ THA } & $-0.0406^{* * * * * k}$ & $0.0054^{\text {seler }}$ & $0.0837^{\text {*opes }}$ & $0.1713^{\text {*ask }}$ & 0.0078 & 0.0051 & $-0.3673^{\text {sepk }}$ & $-0.1379^{* 0 . k+k}$ & $-0.0009^{\text {wopk }}$ & $-8.97^{* * * *}$ & 3524 & 0.9574 \\
\hline & $\{0.0000\}$ & $\{0.0000\}$ & $\{0.0000\}$ & $\{0.0000\}$ & $\{0.6954\}$ & $\{0.9814\}$ & $\{0.0000\}$ & $\{0.0000\}$ & $\{0.0000\}$ & & & \\
\hline
\end{tabular}

$\mathrm{R}$ Rho is correlation coefficient between individual country's foreign currency rating with the average rating of the region it belongs to. 
Table 3. Continued.

\begin{tabular}{|c|c|c|c|c|c|c|c|c|c|c|c|c|}
\hline & $\alpha_{0}$ & $\alpha_{1}$ & $\alpha_{2}$ & $\beta_{0}$ & $\beta_{1}$ & $\beta_{2}$ & $\beta_{3}$ & $\beta_{4}$ & $\beta_{5}$ & Coint-Test & Nobs & R_Rho \\
\hline \multicolumn{13}{|c|}{ EUROPE } \\
\hline \multirow[t]{2}{*}{ CZE } & $0.0578^{* * *}$ & $-0.0052^{* * * *}$ & -0.0017 & $0.0199^{* * * *}$ & 0.0012 & -0.0014 & $-0.0385^{* * *}$ & $-0.0180^{* * *}$ & $-0.0001^{* * *}$ & $-7.76^{* * *}$ & 3524 & 0.0614 \\
\hline & $\{0.0000\}$ & $\{0.0000\}$ & $\{0.9539\}$ & $\{0.0000\}$ & $\{0.8769\}$ & $\{0.9853\}$ & $\{0.0000\}$ & $\{0.0000\}$ & $\{0.0000\}$ & & & \\
\hline \multirow[t]{2}{*}{ GRE } & $-0.1024^{* * * *}$ & $0.0117^{* * *}$ & -0.0298 & $-0.0029^{* * * * *}$ & 0.0012 & 0.0022 & $-0.0098^{* * * *}$ & $0.0022^{* * *}$ & $0.0000^{* * *}$ & $-3.39^{* *}$ & 3524 & 0.7234 \\
\hline & $\{0.0000\}$ & $\{0.0000\}$ & $\{0.3009\}$ & $\{0.0000\}$ & $\{0.7627\}$ & $\{0.8539\}$ & $\{0.0000\}$ & $\{0.0000\}$ & $\{0.0000\}$ & & & \\
\hline \multirow[t]{2}{*}{ POL } & $0.0080^{*}$ & $0.0026^{* * *}$ & -0.0193 & $0.0898^{* * * *}$ & -0.0066 & 0.0384 & $-0.1125^{* * * *}$ & -0.0932 & $0.0001^{* * *}$ & $-12.34^{* * * *}$ & 3482 & 0.6379 \\
\hline & $\{0.0570\}$ & $\{0.0000\}$ & $\{0.3868\}$ & $\{0.0000\}$ & $\{0.7788\}$ & $\{0.4368\}$ & $\{0.0000\}$ & $\{0.0000\}$ & $\{0.0000\}$ & & & \\
\hline \multirow[t]{2}{*}{ RUS } & 0.0032 & $0.0041^{* * *}$ & -0.0104 & $0.0277^{* * *}$ & 0.0047 & -0.0365 & -0.1970 & $-0.0445^{* * * *}$ & $0.0007^{* * *}$ & $-15.06^{* * *}$ & 3403 & 0.8298 \\
\hline & $\{0.4128\}$ & $\{0.0000\}$ & $\{0.7798\}$ & $\{0.0000\}$ & $\{0.7649\}$ & $\{0.7140\}$ & $\{0.0000\}$ & $\{0.0000\}$ & $\{0.0000\}$ & & & \\
\hline \multirow[t]{2}{*}{ TUR } & $0.0040^{* * *}$ & $-0.0011^{* * * *}$ & 0.0011 & $0.0129^{* * *}$ & -0.0045 & 0.0020 & $-1.0249^{* * *}$ & $0.0088^{* * *}$ & $-0.0006^{* * * *}$ & $-24.43^{* * * *}$ & 3524 & 0.3697 \\
\hline & $\{0.0000\}$ & $\{0.0000\}$ & $\{0.6242\}$ & $\{0.0000\}$ & $\{0.5109\}$ & $\{0.8931\}$ & $\{0.0000\}$ & $\{0.0000\}$ & $\{0.0000\}$ & & & \\
\hline \multicolumn{13}{|c|}{ LATIN AMERICA } \\
\hline \multirow[t]{2}{*}{ ARG } & $0.4204^{* * * *}$ & $0.0147^{* * *}$ & $0.6172^{* * *}$ & $0.0006^{* * *}$ & 0.0006 & -0.0022 & $-0.0071^{* * *}$ & $-0.0014^{* * * *}$ & $0.0000^{* * * *}$ & $-3.88^{* * *}$ & 3393 & 0.9267 \\
\hline & $\{0.0000\}$ & $\{0.0000\}$ & $\{0.0007\}$ & $\{0.0001\}$ & $\{0.7579\}$ & $\{0.9716\}$ & $\{0.0000\}$ & $\{0.0000\}$ & $\{0.0000\}$ & & & \\
\hline \multirow[t]{2}{*}{ BRA } & $0.6695^{\text {*** }}$ & 0.0328 & 0.0160 & -0.0331 & -0.0048 & -0.0158 & $-0.1252^{* * * *}$ & 0.0253 & 0.0003 & $-13.17^{* * * *}$ & 3393 & 0.1909 \\
\hline & $\{0.0000\}$ & $\{0.0000\}$ & $\{0.4376\}$ & $\{0.0000\}$ & $\{0.8224\}$ & $\{0.6988\}$ & $\{0.0000\}$ & $\{0.0000\}$ & $\{0.0000\}$ & & & \\
\hline \multirow[t]{2}{*}{ MEX } & $0.4820^{* * *}$ & $0.0188^{* * *}$ & $0.0339^{*}$ & $-0.0088^{* * * *}$ & -0.0187 & -0.0192 & $-0.1310^{* * * *}$ & $0.0043^{* * *}$ & $0.0006^{* * *}$ & $-12.44^{* * * *}$ & 3393 & -0.4334 \\
\hline & $\{0.0000\}$ & $\{0.0000\}$ & $\{0.0558\}$ & $\{0.0000\}$ & $\{0.5065\}$ & $\{0.5503\}$ & $\{0.0000\}$ & $\{0.0000\}$ & $\{0.0000\}$ & & & \\
\hline \multirow[t]{2}{*}{ PER } & -0.2626 & 0.0434 & 0.0498 *** & -0.0983 & 0.0243 & -0.0891 & $-0.3167^{* * *}$ & $0.0980^{* * * *}$ & $0.0015^{* * *}$ & $-10.37^{* * *}$ & 3393 & 0.7400 \\
\hline & $\{0.0000\}$ & $\{0.0000\}$ & $\{0.0009\}$ & $\{0.0000\}$ & $\{0.9047\}$ & $\{0.1086\}$ & $\{0.0000\}$ & $\{0.0000\}$ & $\{0.0000\}$ & & & \\
\hline \multicolumn{13}{|c|}{ MIDDEL EAST AND AFRICA } \\
\hline \multirow[t]{2}{*}{ ISR } & $-0.2523^{* * * *}$ & $0.0335^{* * *}$ & $-0.0382^{* * *}$ & $0.0305^{* * *}$ & -0.0008 & -0.0691 & $-0.6884^{* * *}$ & $-0.0634^{* * *}$ & $-0.0023^{* * *}$ & $-7.12^{* * *}$ & 3524 & \\
\hline & $\{0.0000\}$ & $\{0.0000\}$ & $\{0.0000\}$ & $\{0.0000\}$ & $\{0.3317\}$ & $\{0.8008\}$ & $\{0.0000\}$ & $\{0.0000\}$ & $\{0.0000\}$ & & & \\
\hline \multirow[t]{2}{*}{ SAF } & $0.0175^{* * *}$ & $0.0193^{* * * *}$ & 0.0770 & $0.0020^{* * *}$ & 0.0031 & -0.0432 & $-0.0594^{* * *}$ & $-0.0018^{* * * *}$ & $0.0001^{* * *}$ & $-10.11^{* * * *}$ & 3524 & \\
\hline & $\{0.0074\}$ & $\{0.0000\}$ & $\{0.1099\}$ & $\{0.0000\}$ & $\{0.8821\}$ & $\{0.6821\}$ & $\{0.0000\}$ & $\{0.0000\}$ & $\{0.0004\}$ & & & \\
\hline
\end{tabular}




\section{Table 4. ECM Estimation Results: Sovereign Rating and Outlook Effects on Bond Market Co-movements}

In this table, the estimates for bond market co-movements are shown. The model estimated is defined in Eq. (4)

$$
\begin{gathered}
\operatorname{DCC}_{i j, t}=\alpha_{0 i}+\alpha_{1 i} \text { Rating }_{i, t}+\alpha_{2 i} \text { Outlook }_{i, t}+\varepsilon_{i, t} \\
\Delta D C C_{i j, t}=\beta_{0 i}+\beta_{1 i} \Delta \text { Rating }_{i, t}+\beta_{2 i} \text { OOutlook }_{i, t}+\beta_{3 i} \varepsilon_{i, t-1}+\beta_{4 i} \text { FXVOL }_{i, t}+\beta_{5 i} \text { VIX }_{i, t}+u_{i, t}(4)
\end{gathered}
$$

where the dependent variable is the estimated time-varying bond market correlation of country $i$ at time $t$ with its regional index, Rating $g_{i, t}=F C R a t i n g_{i, t}$ is the foreign currency sovereign credit ratings for country $i$ at time, Outlook $k_{i, t}=F C O u t l o o k_{i, t}$ is the foreign currency sovereign credit outlooks for country $i$ at time, $F X V l_{i, t}=$ exchange rate volatility of country $i$ at time $t$, and $V I X_{\mathrm{i}, \mathrm{t}}=\mathrm{CBO}$ 's Volatility Index (VIX) of country $i$ at time $t$

Notes: P-values are shown in brackets and ***,*** denote significance at the $10 \%, 5 \%$ and $1 \%$ level, respectively. To allow for a meaningful comparison across estimations, results presented are for those sample countries for which we were able to obtain data to generate both stock and bond market regional co-movements. Coint-Test shows the unit root test statistic for $\varepsilon_{i, t}$ where the null is I(1) where significance suggests cointegration.

\begin{tabular}{|c|c|c|c|c|c|c|c|c|c|c|c|c|}
\hline & $\alpha_{0}$ & $\alpha_{1}$ & $\alpha_{2}$ & $\beta_{0}$ & $\beta_{1}$ & $\beta_{2}$ & $\beta_{3}$ & $\beta_{4}$ & $\beta_{5}$ & Coint-Test & Nobs & R_Rho \\
\hline \multicolumn{13}{|c|}{ ASIA } \\
\hline \multirow[t]{2}{*}{$\overline{\mathrm{HKG}}$} & $-0.4379^{* * * * *}$ & $0.0437^{* * *}$ & -0.1180 & $0.5117^{\text {sole }}$ & 0.0030 & $0.0343^{\text {*** }}$ & $-0.0139^{* 0 k k}$ & $-0.5109^{* 0 k k}$ & $0.0000^{* *}$ & $-5.02^{* * *}$ & 3524 & -0.0730 \\
\hline & $\{0.0000\}$ & $\{0.0000\}$ & $\{0.3692\}$ & $\{0.0000\}$ & $\{0.4390\}$ & $\{0.0161\}$ & $\{0.0000\}$ & $\{0.0000\}$ & $\{0.0442\}$ & & & \\
\hline \multirow[t]{2}{*}{ IDO } & 0.7852 & 0.0009 & -0.0898 & 0.0132 & 0.0007 & 0.0192 & -0.0556 & -0.0207 & 0.0001 * & $-9.82^{* * *}$ & 3524 & 0.9647 \\
\hline & $\{0.0000\}$ & $\{0.6740\}$ & $\{0.3079\}$ & $\{0.0000\}$ & $\{0.9427\}$ & $\{0.8451\}$ & $\{0.0000\}$ & $\{0.0000\}$ & $\{0.0532\}$ & & & \\
\hline \multirow[t]{2}{*}{ PHI } & $-0.4851^{* * * *}$ & $0.0860^{* * *}$ & 0.0239 & $-0.0085^{* * * *}$ & 0.0005 & 0.0149 & $-0.0413^{* * * k}$ & $0.0050^{* * * *}$ & $0.0002^{* * *}$ & $-5.98^{* *}$ & 2086 & -0.6414 \\
\hline & $\{0.0000\}$ & $\{0.0000\}$ & $\{0.8782\}$ & $\{0.0000\}$ & $\{0.9998\}$ & $\{0.9547\}$ & $\{0.0000\}$ & $\{0.0000\}$ & $\{0.0000\}$ & & & \\
\hline \multirow[t]{2}{*}{ KOR } & 1.0053 & -0.0219 & -0.4851 & $-0.1085^{* \text { *op }}$ & -0.0014 & 0.0333 & $-0.0173^{\text {teres }}$ & 0.1070 & -0.0001 & $-4.98^{* *}$ & 2982 & 0.8754 \\
\hline & $\{0.0000\}$ & $\{0.0000\}$ & $\{0.0157\}$ & $\{0.0000\}$ & $\{0.6919\}$ & $\{0.7895\}$ & $\{0.0000\}$ & $\{0.0000\}$ & $\{0.0000\}$ & & & \\
\hline \multirow[t]{2}{*}{ TAI } & $2.6215^{* 0 k k}$ & $-0.0955^{*}$ & -0.2501 & -0.3750 & $-0.0466^{*}$ & -0.0547 & -0.0341 & $0.3561^{* 00 k}$ & $0.0001^{* *}$ & $-6.93^{* *}$ & 2982 & 0.2036 \\
\hline & $\{0.0000\}$ & $\{0.0000\}$ & $\{0.1131\}$ & $\{0.0000\}$ & $\{0.0897\}$ & $\{0.6457\}$ & $\{0.0000\}$ & $\{0.0000\}$ & $\{0.0231\}$ & & & \\
\hline \multirow[t]{2}{*}{ THA } & $1.2595^{\text {***** }}$ & -0.0395 & 0.1784 & -0.0195 & -0.0004 & -0.0019 & -0.0131 & 0.0172 & 0.0001 * & $-5.59^{* *}$ & 3524 & 0.9535 \\
\hline & $\{0.0000\}$ & $\{0.0000\}$ & $\{0.6882\}$ & $\{0.0000\}$ & $\{0.9752\}$ & $\{0.9929\}$ & $\{0.0000\}$ & $\{0.0000\}$ & $\{0.0168\}$ & & & \\
\hline
\end{tabular}
$\mathrm{R}$ Rho is correlation coefficient between individual country's foreign currency rating with the average rating of the region it belongs to. 
Table 4. Continued.

\begin{tabular}{|c|c|c|c|c|c|c|c|c|c|c|c|c|}
\hline & $\alpha_{0}$ & $\alpha_{1}$ & $\alpha_{2}$ & $\beta_{0}$ & $\beta_{1}$ & $\beta_{2}$ & $\beta_{3}$ & $\beta_{4}$ & $\beta_{5}$ & Coint-Test & Nobs & R_Rho \\
\hline \multicolumn{13}{|c|}{ EUROPE } \\
\hline \multirow[t]{2}{*}{$\mathrm{CZE}$} & $0.2236^{* * *}$ & 0.0001 & $-0.6329^{* *}$ & $0.0793^{* * *}$ & 0.0001 & -0.0290 & $-0.0189^{* * * *}$ & $-0.0654^{* * * *}$ & $-0.0003^{* * *}$ & $-5.43^{* *}$ & 3524 & 0.1990 \\
\hline & $\{0.0000\}$ & $\{0.9756\}$ & $\{0.0184\}$ & $\{0.0000\}$ & $\{0.9984\}$ & $\{0.9654\}$ & $\{0.0000\}$ & $\{0.0000\}$ & $\{0.0000\}$ & & & \\
\hline GRE & $\{0.0000\}$ & $\{0.0000\}$ & $\{0.0027\}$ & $\{0.0000\}$ & $\{0.7831\}$ & $\{0.8201\}$ & $\{0.0000\}$ & $\{0.0000\}$ & $\{0.1774\}$ & & & \\
\hline \multirow[t]{2}{*}{ POL } & $0.7704^{* * *}$ & $-0.0235^{* * *}$ & $-0.3287^{* * *}$ & $0.7795^{* * *}$ & $-0.1707^{*}$ & -0.4281 & $-1.0085^{* * *}$ & $-0.8651^{* * * *}$ & $-0.0032^{* * *}$ & $-10.91^{* *}$ & 2086 & 0.8778 \\
\hline & $\{0.0000\}$ & $\{0.0000\}$ & $\{0.0000\}$ & $\{0.0000\}$ & $\{0.0818\}$ & $\{0.4124\}$ & $\{0.0000\}$ & $\{0.0000\}$ & $\{0.0004\}$ & & & \\
\hline \multirow[t]{2}{*}{ SLO } & $0.4937^{* * *}$ & $0.0158^{* * *}$ & 0.1042 & $-0.0840^{* * *}$ & 0.0270 & $0.3005^{* *}$ & $-0.0828^{* * *}$ & $0.0968^{* * *}$ & $-0.0007^{* * *}$ & $-9.90^{* *}$ & 2982 & 0.9141 \\
\hline & $\{0.0000\}$ & $\{0.0000\}$ & $\{0.1831\}$ & $\{0.0000\}$ & $\{0.6426\}$ & $\{0.0353\}$ & $\{0.0000\}$ & $\{0.0000\}$ & $\{0.0000\}$ & & & \\
\hline \multirow[t]{2}{*}{ TUR } & 0.6343 *** & $0.0218^{* * *}$ & -0.1802 & -0.0483 & -0.0035 & $0.0743^{* * *}$ & -0.0503 & $0.0461^{* * *}$ & $0.0000^{*}$ & $-9.69^{* *}$ & 3524 & 0.2381 \\
\hline & $\{0.0000\}$ & $\{0.0000\}$ & $\{0.0071\}$ & $\{0.0000\}$ & $\{0.6970\}$ & $\{0.0000\}$ & $\{0.0000\}$ & $\{0.0000\}$ & $\{0.0990\}$ & & & \\
\hline \multicolumn{13}{|c|}{ LATIN AMERICA } \\
\hline \multirow[t]{2}{*}{ ARG } & $0.2574^{* * *}$ & $-0.0116^{* * *}$ & $-0.3332^{* * *}$ & $-0.1026^{* * *}$ & -0.0017 & 0.0226 & $-0.0671^{* * *}$ & $0.1017^{\text {*** }}$ & $0.0003^{* * *}$ & $-8.98^{* *}$ & 3524 & \\
\hline & $\{0.0000\}$ & $\{0.0000\}$ & $\{0.0024\}$ & $\{0.0000\}$ & $\{0.7494\}$ & $\{0.9088\}$ & $\{0.0000\}$ & $\{0.0000\}$ & $\{0.0000\}$ & & & \\
\hline \multirow[t]{2}{*}{ MEX } & $1.6490^{* * *}$ & $-0.0452^{* * *}$ & -0.0258 & $-0.0343^{* * *}$ & -0.0026 & -0.0052 & $-0.0175^{* * *}$ & $0.0326^{* * *}$ & $-0.0002^{* * *}$ & $-4.36^{* *}$ & 3524 & \\
\hline & $\{0.0000\}$ & $\{0.0000\}$ & $\{0.8751\}$ & $\{0.0000\}$ & $\{0.9345\}$ & $\{0.9466\}$ & $\{0.0000\}$ & $\{0.0000\}$ & $\{0.0000\}$ & & & \\
\hline \multirow[t]{2}{*}{$\overline{\text { ISR }}$} & $3.0431^{* * * *}$ & $-0.1838^{* * *}$ & $0.4012^{* * *}$ & $0.0879^{* * *}$ & -0.0020 & 0.0022 & $-0.0332^{* * * *}$ & $-0.0845^{* * * *}$ & $-0.0001^{* * * *}$ & $-7.76^{* *}$ & 3524 & \\
\hline & $\{0.0000\}$ & $\{0.0000\}$ & $\{0.0057\}$ & $\{0.0000\}$ & $\{0.1644\}$ & $\{0.9941\}$ & $\{0.0000\}$ & $\{0.0000\}$ & $\{0.0006\}$ & & & \\
\hline \multirow[t]{2}{*}{ SAF } & $0.4997^{* * *}$ & $0.0297^{* * *}$ & -0.0708 & $-0.0089^{* * *}$ & $-0.0240^{* * *}$ & -0.0451 & $-0.0328^{* * *}$ & $0.0121^{* * *}$ & $0.0000^{*}$ & $-7.99^{* *}$ & 3524 & \\
\hline & $\{0.0000\}$ & $\{0.0000\}$ & $\{0.1438\}$ & $\{0.0000\}$ & $\{0.0012\}$ & $\{0.3377\}$ & $\{0.0000\}$ & $\{0.0000\}$ & $\{0.0747\}$ & & & \\
\hline
\end{tabular}


Appendix A: Granger causality tests between Ratings/Outlooks and Dynamic Conditional Intra-regional correlations of national equity markets

In this appendix Granger causality test results are summarized. The test equation is $y_{t}=a+\sum_{i=1}^{5} b_{i} y_{t-i}+\sum_{j=1}^{5} c_{i} x_{t-j}$, and the null hypothesis is H0: $x$ does not Granger Cause $y, c_{j}=0$ for all $j$.The test statistics are reported with associated p-values in brackets 


\begin{tabular}{|c|c|c|c|c|c|c|c|c|}
\hline & \multicolumn{2}{|c|}{$\begin{array}{l}\text { H0: DCC does not } \\
\text { G.C. Rating }\end{array}$} & \multicolumn{2}{|c|}{$\begin{array}{c}\text { H0: DCC does not } \\
\text { G.C. Outlook }\end{array}$} & \multicolumn{2}{|c|}{$\begin{array}{l}\text { H0: Rating does not } \\
\text { G.C. DCC }\end{array}$} & \multicolumn{2}{|c|}{$\begin{array}{l}\text { H0: Outlook does not } \\
\text { G.C. DCC }\end{array}$} \\
\hline & Level & First Diff & Level & First Diff & Level & First Diff & Level & First Diff \\
\hline \multicolumn{9}{|l|}{ ASIA } \\
\hline HKG & 0.0000 & 0.0000 & $0.0785 *$ & 0.7028 & 0.4284 & 0.6622 & 0.3484 & 0.3870 \\
\hline IDO & 0.9833 & 0.9853 & $0.0597 *$ & 0.2873 & 0.1443 & 0.2970 & 0.9934 & 0.9992 \\
\hline IND & 0.0000 * & 0.3538 & $0.0659 *$ & 0.1674 & 0.7003 & 0.7008 & 0.2086 & 0.1070 \\
\hline MAL & $0.0088^{* 0 * k}$ & $0.0931 *$ & 0.1606 & $0.0583 *$ & 0.5659 & 0.6294 & 0.5020 & 0.2753 \\
\hline PHI & 0.0000 & 0.4064 & 0.0032 & $0.0045^{\text {* *ot }}$ & 0.7023 & 0.7022 & 0.0886 * & 0.2742 \\
\hline KOR & 0.6578 & 0.6474 & 0.8855 & 0.8479 & 0.1517 & 0.1942 & 0.3107 & 0.3231 \\
\hline TAI & 0.0000 & $0.0000^{\text {*opk }}$ & 0.0007 * & $0.0266^{* *}$ & 0.8492 & 0.8498 & 0.7119 & 0.7026 \\
\hline THA & 0.0003 * & $0.0226 * *$ & $0.0543 *$ & 0.6739 & 0.2509 & 0.4746 & 0.5731 & 0.6220 \\
\hline \multicolumn{9}{|c|}{ EUROPE } \\
\hline $\mathrm{CZE}$ & 0.5211 & 0.0000 * * w & 0.0000 & $0.0000^{* 0 * k}$ & 0.7019 & 0.7019 & 0.8492 & 0.8498 \\
\hline GRE & $0.0253 *$ & $0.0113 * *$ & 0.2429 & 0.2882 & 0.5459 & 0.6075 & 0.5349 & 0.4721 \\
\hline POL & 0.3869 & 0.1790 & 0.1887 & 0.2119 & 0.5626 & 0.6573 & 0.4370 & 0.6731 \\
\hline RUS & 0.6646 & 0.3038 & 0.6029 & 0.3245 & 0.5642 & 0.8564 & 0.5537 & 0.6141 \\
\hline TUR & 0.0031 * & 0.2832 & 0.3287 & 0.3885 & 0.7431 & 0.6159 & 0.3531 & 0.2582 \\
\hline \multicolumn{9}{|c|}{ LATIN AMERICA } \\
\hline ARG & $0.0446 *$ & 0.2502 & 0.1302 & 0.2296 & 0.3945 & 0.5691 & 0.5388 & 0.5182 \\
\hline BRA & $0.0000 *$ & 0.3614 & 0.1026 & $0.0628 *$ & 0.8397 & 0.8749 & 0.5694 & 0.4649 \\
\hline MEX & $0.0829 *$ & 0.6471 & $0.0113 * *$ & $0.0706 *$ & 0.5641 & 0.5626 & 0.5763 & 0.4681 \\
\hline PER & 0.1353 & $0.0847 *$ & 0.2660 & 0.2021 & 0.8516 & 0.8512 & 0.4870 & 0.5108 \\
\hline \multicolumn{9}{|c|}{ MIDDLE EAST AND AFRICA } \\
\hline ISR & $0.0000 *$ & 0.0000 *opk & 0.0000 *ok & 0.0000 & 0.9622 & 0.9626 & 0.5548 & 0.5515 \\
\hline SAF & 0.1600 & 0.9503 & $0.0003^{\text {*ow }}$ & $0.0000^{\text {*owk }}$ & 0.6150 & 0.7409 & 0.5579 & 0.5536 \\
\hline \multicolumn{9}{|c|}{ Number of significant Granger Causality at leat at $10 \%$} \\
\hline & 12 & 8 & 10 & 8 & 0 & 0 & 1 & 0 \\
\hline
\end{tabular}


Appendix B: Granger causality tests between Ratings/Outlooks and Dynamic Conditional Intra-regional Correlations of national bond markets

In this appendix Granger causality test results are summarized. The test equation is $y_{t}=a+\sum_{i=1}^{5} b_{i} y_{t-i}+\sum_{j=1}^{5} c_{i} x_{t-j}$, and the null hypothesis is H0: $x$ does not Granger Cause $y, c_{j}=0$ for all $j$.The test statistics are reported with associated p-values in brackets.

\begin{tabular}{|c|c|c|c|c|c|c|c|c|}
\hline & \multicolumn{2}{|c|}{$\begin{array}{l}\text { H0: DCC does not } \\
\text { G.C. Rating }\end{array}$} & \multicolumn{2}{|c|}{$\begin{array}{c}\text { H0: DCC does not } \\
\text { G.C. Outlook }\end{array}$} & \multicolumn{2}{|c|}{$\begin{array}{l}\text { H0: Rating does not } \\
\text { G.C. DCC }\end{array}$} & \multicolumn{2}{|c|}{$\begin{array}{l}\text { H0: Outlook does not } \\
\text { G.C. DCC }\end{array}$} \\
\hline & Level & First Diff & Level & First Diff & Level & First Diff & Level & First Diff \\
\hline \multicolumn{9}{|l|}{ ASIA } \\
\hline HKG & 0.0709 * & $0.0763 *$ & 0.1829 & 0.1480 & 0.5000 & 0.4673 & 0.7555 & 0.4908 \\
\hline IDO & 0.8816 & 0.8123 & 0.6980 & 0.5124 & 0.4872 & 0.8416 & 0.4728 & 0.3817 \\
\hline PHI & $0.0000^{* * * k}$ & $0.0000^{*+k}$ & $0.0013^{* \text { *k }}$ & 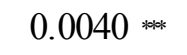 & 0.9629 & 0.9631 & 0.5071 & 0.4826 \\
\hline KOR & 0.7749 & 0.6645 & 0.4570 & 0.4954 & 0.2743 & 0.5742 & 0.5577 & 0.5592 \\
\hline TAI & 0.0027 * * & $0.0274 *$ & $0.0000^{* * k}$ & $0.0000 *$ & 0.8500 & 0.8506 & 0.7053 & 0.7039 \\
\hline THA & $0.0868 *$ & 0.4852 & 0.8888 & 0.3251 & 0.6048 & 0.4290 & 0.6756 & 0.6606 \\
\hline \multicolumn{9}{|c|}{ EURPOE } \\
\hline $\mathrm{CZE}$ & 0.9754 & 0.8044 & $0.0000^{* 0 k}$ & $0.0000^{* * * k}$ & 0.7131 & 0.7144 & 0.8542 & 0.8523 \\
\hline GRE & 0.0000 & $0.0005^{* * * k}$ & $0.0402 *$ & $0.0131 *$ & 0.8328 & 0.6777 & 0.5641 & 0.6969 \\
\hline POL & 0.4773 & $0.0481^{* *}$ & 0.7872 & 0.8825 & 0.7053 & 0.7030 & 0.4804 & 0.4414 \\
\hline SLO & $0.0052^{* * * * *}$ & 0.1418 & 0.3912 & 0.2676 & 0.2606 & 0.4238 & 0.5568 & 0.5564 \\
\hline TUR & $0.0156 *$ & 0.1589 & $0.0114 *$ & 0.1209 & 0.3751 & 0.5210 & 0.7186 & 0.6928 \\
\hline \multicolumn{9}{|c|}{ LATIN AMERICA } \\
\hline ARG & $0.0107^{* *}$ & 0.0117 ** & $0.0127^{* *}$ & 0.2393 & 0.1265 & 0.5534 & 0.5599 & 0.8171 \\
\hline MEX & 0.5992 & 0.3867 & 0.5715 & 0.5440 & 0.6592 & 0.7595 & 0.5349 & 0.4828 \\
\hline \multicolumn{9}{|c|}{ MIDDLE EAST AND AFRICA } \\
\hline ISR & $0.0000 *$ & $0.0000^{*}$ & $0.0494 *$ & 0.2388 & 0.9624 & 0.9634 & 0.6649 & 0.6294 \\
\hline SAF & 0.0000 *** & 0.2938 & $0.0647 *$ & 0.3275 & 0.6446 & 0.6301 & 0.5917 & 0.5821 \\
\hline \multicolumn{9}{|c|}{ Number of significant Granger Causality at leat at $10 \%$} \\
\hline & 10 & 7 & 8 & 4 & 0 & 0 & 0 & 0 \\
\hline
\end{tabular}

